\title{
Eurytoma serratulae and E. robusta (Hymenoptera, Eurytomidae): complementary host exploitation strategies of coexisting parasitoids and their impact on the host Urophora cardui
}

\author{
Helmut Zwölfer', Marc Böheim², Erwin Beck ${ }^{3}$ \\ I University of Bayreuth, clo Ecological-botanical garden, D 95440 Bayreuth, Germany 2 os. Moje Marzenic \\ 11E, 78-600 Walez, Poland 3 University of Bayreuth, Bayreuth Center of Ecology and Environmental Rese- \\ arch, Universitaetsstr. 30, D 95440 Bayreuth, Germany
}

Corresponding author: Helmut Zwölfer (h.zwoelfer@gmx.net)

Academic editor: Mark Shaw | Received 28 October 2014 | Accepted 9 January 2015 | Published 18 March 2015

http://zoobank.org/94CF66EC-F11F-45B6-89BC-159530E4A2EE

Citation: Zwölfer H, Böheim M, Beck E (2015) Eurytoma serratulae and E. robusta (Hymenoptera, Eurytomidae): complementary host exploitation strategies of coexisting parasitoids and their impact on the host Urophora cardui. Journal of Hymenoptera Research 42: 47-62. doi: 10.3897/JHR.42.8847

\begin{abstract}
Our study investigates the host exploitation strategies of Eurytoma serratulae and E. robusta (Chalcidoidea, Eurytomidae), two parasitoid species that co-occur in gall populations of the tephritid Urophora cardui on Cirsium spp. The endoparasitoid E. serratulae detects the host larvae before an externally visible gall is formed. It profits from large galls, as its parasitization rate increases with increasing numbers of chambers per gall. Oviposition by the ectoparasitoid E. robusta does not occur until a distinct gall with chambers has been formed. Its parasitization rate reaches highest values in medium-sized galls. Eurytoma robusta is the dominant parasitoid in host populations with low and moderate gall densities, whereas E. serratulae is the superior exploiter of host populations with high gall densities. Within single galls E. robusta is an important hyperparasitoid of E. serratulae, but E. serratulae has no adverse influence on E. robusta. Parasitism by E. serratulae induces host larvae to promote gall growth, an effect that is profitable to both the parasitoid and the remaining host larvae in the gall. Parasitism by E. robusta often leads to smaller galls, as cases of unsuccessful parasitization result in empty gall cells.
\end{abstract}

\section{Keywords}

Urophora cardui galls, coexistence of Eurytoma, parasitoid-interactions, stimulation of gall growth

Copyright Helmut Zwölfer et al. This is an open access article distributed under the terms of the Creative Commons Attribution License (CC BY 4.0), which permits unrestricted use, distribution, and reproduction in any medium, provided the original author and source are credited. 


\section{Introduction}

A competitive coexistence of generalists and specialists is a common and well-studied feature of parasitoid guilds exploiting phytophagous hosts (e.g. Smith 1929, Zwölfer and Kraus 1957, Fisher 1961, Askew 1968, Godfray 1994). A particular case is the coexistence of pairs of competing congeners, a situation found in Eurytoma species (Chalcidoidea, Eurytomidae) associated with gall forming tephritids: thus Eurytoma compressa (Fabricius) ( = curta (Walker)) and E. robusta Mayr coexist in hosts living in Cardueae flower head galls (Zwölfer and Arnold-Rinehart 1993), and Eurytoma obtusiventris Gahan and E. gigantea Walsh in stem galls of North American Solidago spp. (Abrahamson and Weis 1997). The parasitoids Eurytoma serratulae (Fabricius) and E. robusta regularly co-occur in gall populations of the tephritid Urophora cardui (Linnaeus) on shoots of Creeping Thistle (Cirsium arvense). Information on the biology of E. serratulae and E. robusta has been published by Claridge (1961), Redfern (1983), Redfern and Askew (1992) and Zwölfer (1979, 1988). In view of considerable differences in its larval biology E. robusta has been placed in a separate species group of Eurytoma (e.g. Zerova and Seryogina 2006). Both species are solitary parasitoids.

Our study investigates the mechanisms that make the coexistence of the two Eurytoma species possible. The characteristics of the multilocular gall of $U$. cardui allow comparing the behaviour of the two Eurytoma species on the level of the microhabitat of individual galls and on the macrohabitat level of the gall populations. For both levels we compare the exploitation strategies of E. serratulae and E. robusta using our large basis of field-collected data that allow the statistical evaluation of "natural experiments". We analyse the influence of gall size and gall densities in the field on the incidence, degree of parasitism and the exploitation pattern of the two Eurytoma species. In conclusion we compare the effect of $E$. serratulae and E. robusta on the growth of $U$. cardui galls and we discuss how the characteristic features of the multilocular galls of $U$. cardui and the specialized oviposition behaviour safeguard E. serratulae against an overexploitation of its resource.

\section{Methods and material}

Collections. For our study we combined cage observations on the behaviour of E. serratulae with the statistical analysis of field collected gall populations. For the evaluation of our field data we disposed of 693 gall samples (16 732 galls) of $C$. arvense and nine samples (374 galls) of $C$. creticum. The $C$. arvense galls were collected between the years 1969 and 2006 in France, Switzerland, northern Italy, Germany, Austria, Slovakia, southern England, and western Poland, the C. creticum-galls in 1984 and 1990 in northern Greece. Galls were collected from September / October to March / April. Urophora cardui populations frequently occur in the form of metapopulations (Eber and Brandl 1994), i.e. as a network of single demes (Saccheri and Hanski 2006). We treated a thistle patch with $U$. cardui galls as a "popula- 
tion" if it was separated from a neighbouring patch with galls by at least $200 \mathrm{~m}$. We counted the number of thistle shoots and galls / patch in the field, estimated the total number of shoots / patch and dissected the galls under a stereomicroscope. We assessed the gall content (living or dead larvae or pupae of $U$. cardui, E. serratulae, E. robusta and other parasitoids, empty chambers, eggs of $E$. robusta) and gall size (cell number and gall diameter). All data were assessed in SPSS files by the program DATA ENTRY and analysed by IBM SPSS statistics 21 . For the path analysis we followed Sokal and Rohlf (1981).

Host ranges and distribution of Eurytoma serratulae and E. robusta. Eurytoma serratulae is an endoparasitoid of Urophora cardui. Claridge (1961) showed that E. tristis Mayr, which Mayr (1878) and other authors recorded from galls of $U$. cardui, is synonymous with $E$. serratulae. All reliable host records of $E$. serratulae refer to $U$. cardui, a tephritid whose host plants are Cirsium arvense (Claridge 1961), C. creticum (Zwölfer 1988) and C. setosum (Frenzel et al. 2000). The ectoparasitoid Eurytoma robusta can so far only be identified as a morphospecies, the host records in the literature may actually pertain to a cluster of undescribed siblings. Claridge (1961) describes $E$. robusta as attacking "a wide range of tephritid galls on Cardueae host plants". Zwölfer and Arnold-Rinehart (1993) list E. robusta from 14 Palearctic Urophora species on 22 Cardueae host plant species.

Both parasitoids have been reared from $U$. cardui galls on $C$. arvense in England (Claridge 1961), Switzerland, France, Germany and Austria (Zwölfer 1979, 1994), and Finland (Vikberg 2005). Additional records from U. cardui on C. arvense are from northern Italy, western Poland and Slovakia $(H$. Zwölfer, unpublished). The two Eurytoma species also coexist in U. cardui galls on C. creticum in northern Greece (Zwölfer 1988) and in U. cardui galls on C. setosum originating from the Ural Mountains (Frenzel et al. 2000). Thus, the two Eurytoma species attack Urophora cardui on all 3 host plants and in almost all regions where galls have been analysed. An exception is Denmark and Schleswig-Holstein (northern Germany), where Johannesen and Seitz (2003a, b) as well as we (H. Zwölfer, unpublished) found only E. robusta in $U$. cardui galls. There, the examined thistle patches with $U$. cardui may have been recently recolonized by $U$. cardui (Johannesen and Seitz 2003b). Parasitoids of minor importance in $U$. cardui galls are the ectoparasitoids Torymus chloromerus (Walker) (Torymidae) and Pteromalus elevatus (Walker) (Pteromalidae).

\section{Biology of Eurytoma serratulae and E. robusta}

Eurytoma serratulae is a koinobiont (Askew and Shaw 1986) endoparasitoid. Oviposition takes place in early summer, shortly after the start of the oviposition period of $U$. cardui. The E. serratulae females detect the host larvae in thistle shoots, before a visible growth of the gall had occurred (Zwölfer 1979) and deposit their eggs into the young host larvae. This early attack on the hosts has the advantage that there is no constraint 
on the length of the ovipositor (Price and Clancy 1986). The young E. serratulae larva remains in developmental stasis within the growing $U$. cardui larva until the host larva is full-grown in early autumn. Then, the parasitoid larva consumes its host and induces a sclerotization of the cuticula of the host (Claridge 1961). This process might provide some protection against hyperparasitoids or predators penetrating into the gall. The mature parasitoid larva spends the winter within this mummy, which externally resembles a pupated U. cardui larva. Pupation of E. serratulae occurs in the following spring, emergence of the adults in early summer.

Eurytoma robusta is an idiobiont (Askew and Shaw 1986). Its females lay their eggs into the chambers of more advanced stages of $U$. cardui galls. The hatching larvae exploit the host larvae as an ectoparasitoid. The mature larvae hibernate within the gall chambers, they pupate in spring and the adults emerge 2-3 weeks later than those of $E$. serratulae. Eurytoma robusta is a hyperparasitoid of E. serratulae, if it consumes a host larva already attacked by a young larva of the congener. Within an individual gall an E. robusta larva may feed on and kill more than one host. Due to poor synchronization young host larvae are often killed and consumed before they have developed enough biomass to allow the maturation of the E. robusta larva. If nutritive gall tissue is still available, the E. robusta larvae may switch to it, thus acting as an inquiline (Redfern and Askew 1992). Eurytoma robusta often suffers from a high incidence of superparasitism. Zwölfer et al. (2007) give a detailed description of the biology of E. robusta and the part it plays in the population dynamics of its host U. cardui.

\section{Results}

\section{E. serratulae and $E$. robusta: the influence of gall size (number of cells)}

To assess the role of gall size for the parasitization pattern we use data from 260 gall samples with a total of 7,064 galls collected from 1976 to 1993 in eastern France, southern Germany and eastern Austria. The number of cells / gall ranged from one to $18($ mean $+\mathrm{SE}=3.807+0.045$, median $=3)$. A total of $25 \%$ of the galls had more than five cells and $10 \%$ more than 6 cells. Incidence of parasitism (\% galls attacked) by $E$. serratulae increases steadily with increasing gall size, whereas attack rate by $E$. robusta reaches a maximum at intermediate gall sizes (Fig. 1). A corresponding pattern exists, if the average number of Eurytoma larvae / gall is examined (Fig. 2). The different trends of parasitization by E. serratulae and E. robusta are also recognizable in Fig. 3, which compares the average content of single galls of the different size classes. The graph includes the galls with empty cells, which usually are caused by $E$. robusta (Zwölfer et al. 2007). This species is represented together with a small ( $<5 \%)$ proportion of Pteromalus elevatus, a rare ectoparasitoid of $U$. cardui. The clear winner of an increasing gall size is the host, $U$. cardui (Freese and Zwölfer 1996). Because of interactions with other mortality factors of $U$. cardui, the correlation of E. serratulae with gall size (cells / gall) is weak (Spearman rank correlation: $r_{s}=0.236, T=20.72$, 


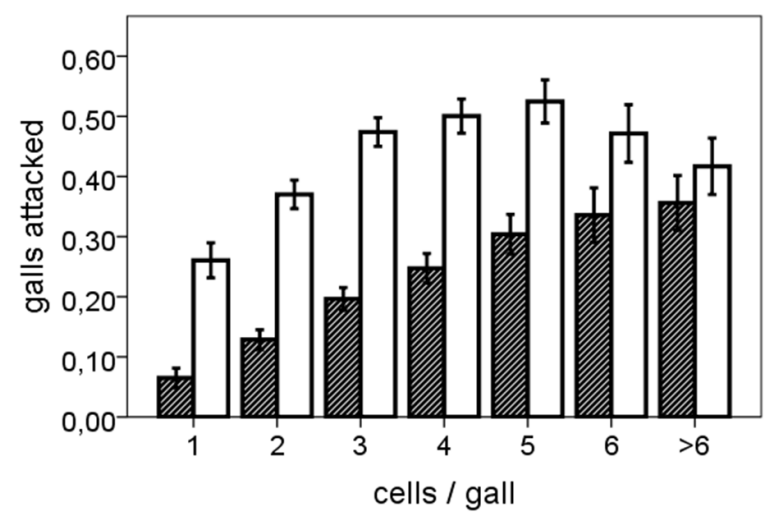

Figure I. Average attack rate of galls by E. serratulae (black) and E. robusta (white) as function of cell numbers per gall. Analysed material: 260 gall samples with a total of 7,064 galls collected from 1976 to 1993 in eastern France, southern Germany and eastern Austria.

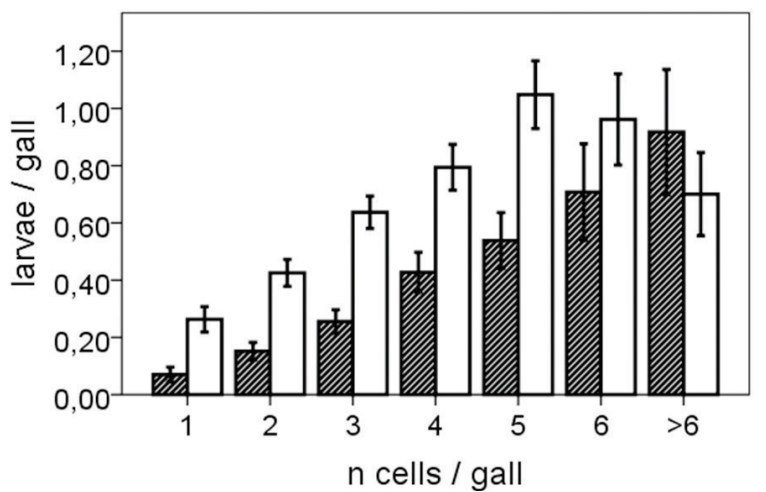

Figure 2. Average frequency of E. serratulae (black) and E. robusta (white) larvae as function of cell numbers per gall. Analysed material: 260 gall samples with a total of 7,064 galls collected from 1976 to 1993 in eastern France, southern Germany and eastern Austria.

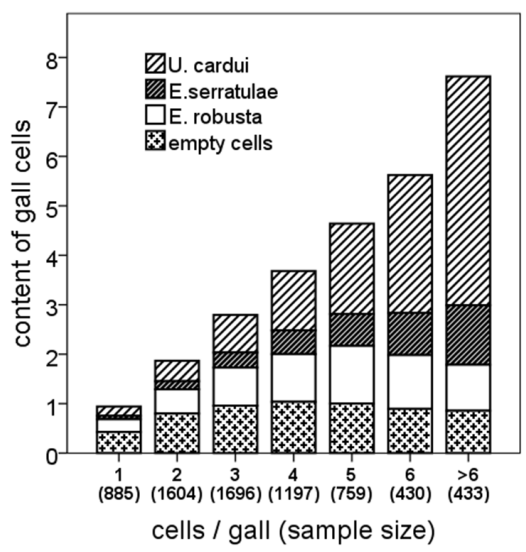

Figure 3. Average content of galls as a function of cell numbers / gall. (In parentheses: number of galls examined). 


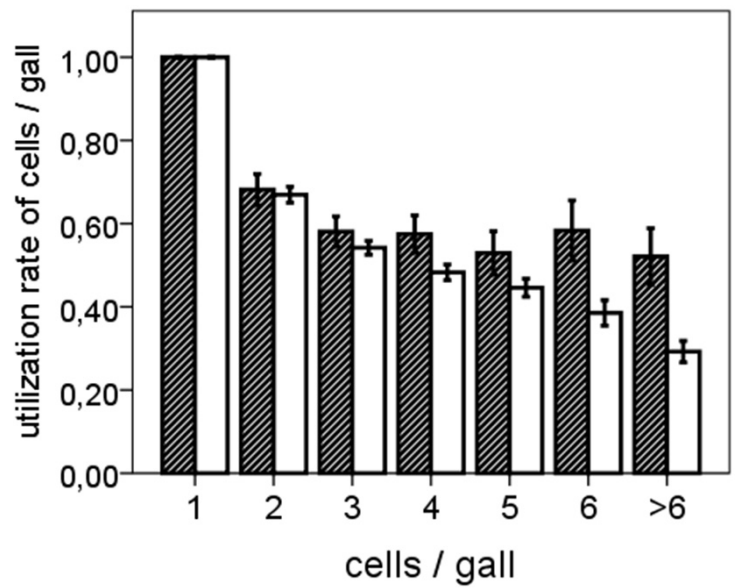

Figure 4. Average exploitation rate of galls attacked by E. serratulae (black) and/or E. robusta (white) as a function of gall size (cells / gall). Material: E. serratulae: 1407 galls; E. robusta: 1509 galls.

$p<0.001, N=6971)$. It becomes much stronger $\left(r_{s}=0.604, T=12.305, p<0.001\right.$, $N=270$ ), if the analysis is restricted to galls parasitized by E. serratulae without other mortality factors (e.g. E. robusta or empty chambers).

The mean exploitation rate of the cells of a gall drops in both Eurytoma species with an increasing number of cells / gall (Fig. 4). In E. robusta it decreases from $60-70 \%$ in small galls to $20 \%$ in galls with more than seven chambers. In E. serratulae the trend remains constant with a rate of about $40 \%$ in medium-sized and large galls. Therefore E. serratulae profits from $U$. cardui populations with large galls more than E. robusta. The difference between the two species is significant $(p<0.001)$.

\section{E. serratulae and E. robusta: interactions at the level of single galls}

Since E. robusta oviposits later than E. serratulae, we expected an asymmetric relationship between the two Eurytoma species. For a statistical test the effect of gall size on the rate of parasitization had to be removed. If galls occupied by E. serratulae without its congener are compared with galls jointly occupied by both species together (Fig. 5), the presence of E. robusta in a gall leads to a lower proportion of E. serratulae larvae (means of 1.87 vs 2.18 larvae / gall, ANOVA: $F=16.5$, DF $=1 / 1405, p<0.001)$. We interpret the difference as loss of $E$. serratulae due to hyperparasitism by $E$. robusta. For $E$. robusta the presence of $E$. serratulae has no significant effect (means of 1.74 and 1.75 larvae / gall, ANOVA: $F=0.11, \mathrm{DF}=1 /$ 2979, $p=0.743$ ). Since cases in which all $E$. serratulae larvae have been eliminated by $E$. robusta could not be assessed, the data in Fig. 5 do not represent the entire extent of mortality of $E$. serratulae due to E. robusta. 


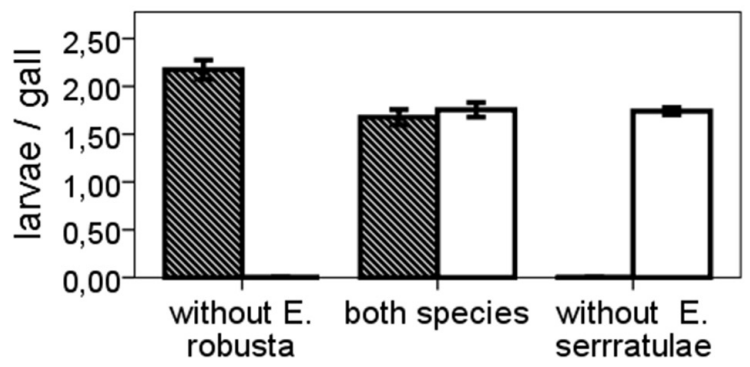

Figure 5. Asymmetric interaction between the E. serratulae (black) and E. robusta (white): Average numbers of E. serratulae/gall without E. robusta (381 galls); E. serratulae together with E. robusta (324 galls); E. robusta without E. serratulae (2454 galls).

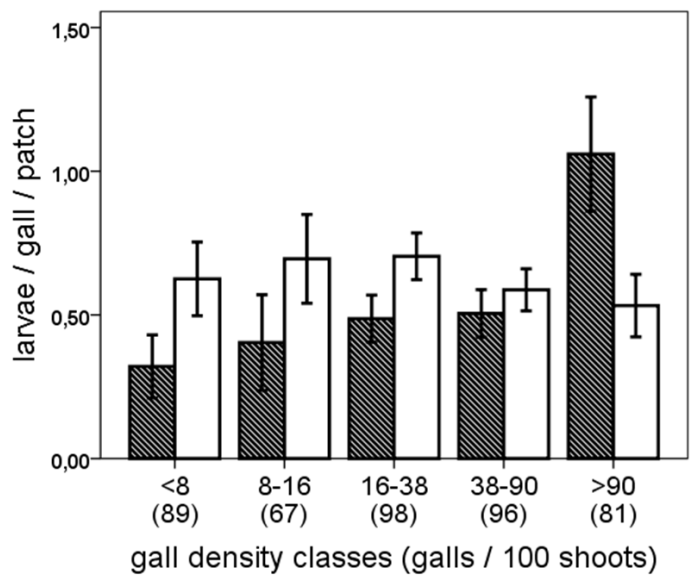

Figure 6. The influence of gall density / thistle patch (= galls / 100 thistle shoots) on E. serratulae (black) and E. robusta (white). (In parentheses: number of galls examined).

\section{E. serratulae and E. robusta: comparison of gall populations}

Our material allows comparing the two Eurytoma spp. with regard to gall density / thistle patch, which is a rough estimate of the quantity of galls in a thistle patch ( $E$. serratulae $=688$ samples; $E$. robusta $=1093$ samples). The analysed samples represent average densities of locally and temporally fluctuating parasitoid-host complexes (Zwölfer 1994, Zwölfer et al. 2007). If analysed for five classes of sample sizes (Fig. 6) the average parasitism of E. serratulae and E. robusta is significantly different only in populations with low and high gall densities. In isolated galls and small clusters of galls E. robusta reaches larval densities twice as large as E. serratulae. The opposite situation occurs in thistle patches where the host population has reached peak gall densities. The rate of parasitism by $E$. serratulae increases steadily with increasing gall densities (Spearman correlation: $r_{s}=0.399, N=670$ populations, $p<0.001$ ), whereas E. robusta 


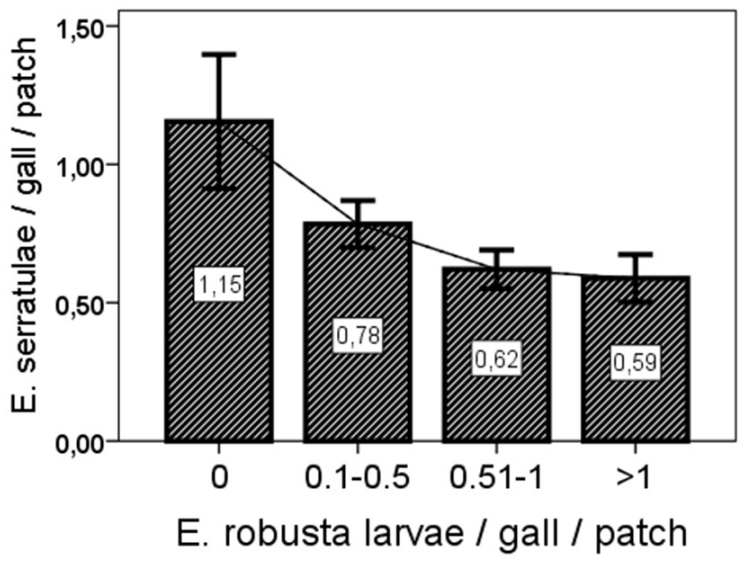

Figure 7. Average numbers of E. serratulae larvae / gall in $U$. cardui populations with different parasitization rates of E. robusta. (Sample sizes: 227, 332, 295, 209 gall populations).

reaches highest values in patches with intermediate gall densities $(F=3.589, \mathrm{DF}=4$ / $437, p=0.007)$. Eurytoma serratulae profits from phases with high gall density, while E. robusta takes over at low and intermediate gall densities. The pattern suggests differences in the host searching behaviour of the two species, but an additional effect that favours E. serratulae at high host densities may be the reduced load of hyperparasitism by $E$. robusta. A general linear model was used to disentangle the effects of sample size and gall density. Sample size is statistically not significant (E. serratulae: DF $=4$, $F=0.577, p=0.679 ;$ E. robusta: $\mathrm{DF}=4, F=0.500, p=0.736)$, but the effect of gall density is highly significant $(E$. serratulae: $\mathrm{DF}=4, F=10.428, p<0.001 ; E$. robusta: $\mathrm{DF}=4, F=3.739, p<0.001)$, and the interaction between the two factors is weak $(E$. serratulae: $\mathrm{DF}=15, F=1.740, p=0.040 ;$ E. robusta: $\mathrm{DF}=15, F=1.774, p=0.035)$.

Fig. 7 shows that the average number of E. serratulae larvae / gall / sample reaches the highest value in gall populations without E. robusta and sinks significantly with increasing numbers of $E$. robusta larvae ( $N$ samples: $227,332,295,209, \mathrm{DF}=3, F=$ $4.723, p=0.003$ ). We interpret the data as an average mortality of $40-50 \%$ due to hyperparasitism and empty cells caused by E. robusta. If the average density of E. robusta larvae is compared for samples without $(N=357)$ and with $(N=691)$ E. serratulae, there is an increase of 0.57 to 0.65 E. robusta larvae /gall / sample. This weak statistical effect (DF $=1, F=4.033, p=0.045)$ with the factor "E. serratulae" is due to the fact that E. serratulae has the tendency to occur in higher numbers in galls with more chambers, which favour also E. robusta.

Hyperparasitism by E. robusta masks in most gall populations the superior capacity of $E$. serratulae to use the cells of the multilocular $U$. cardui galls. In 119 gall populations with less than 0.011 E. robusta larvae / gall / sample an average of $27.9 \%$ of the available cells where parasitized by E. serratulae, whereas E. robusta (605 populations with low or without parasitism by $E$. serratulae) used only $21.8 \%$. The difference is significant $(T$-test: $p<0.001)$. 


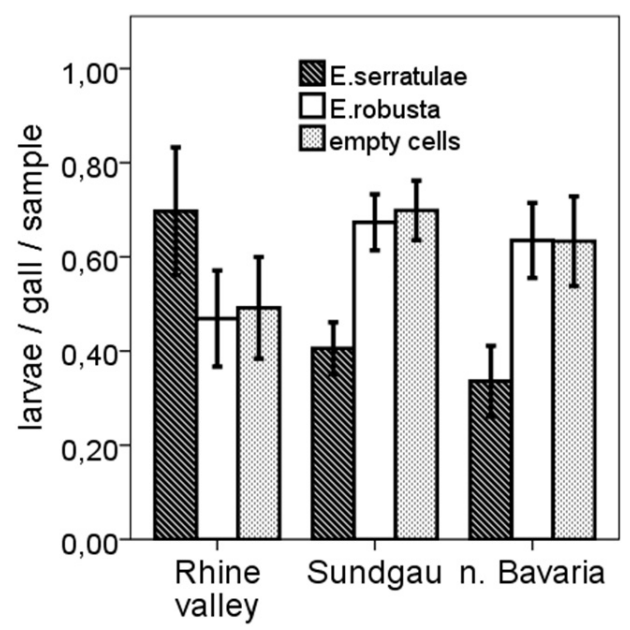

Figure 8. Parasitization of $U$. cardui samples by E. serratulae and E robusta in 3 different regions of western Europe. Sundgau (France, region of Belfort): 307 samples, 6463 galls (19702004); Upper Rhine Valley ( region n.w. Freiburg): 78 samples, 1885 galls (1972-1992); North eastern Bavaria (region s.e. Bayreuth): 216 samples, 4131 galls (1978-2004).

\section{E. serratulae and E. robusta: regional differences}

The parasitization rates of E. serratulae and E. robusta vary temporally and locally with the population dynamics of $U$. cardui (Zwölfer et al. 2007). These fluctuations are superimposed by regional differences (Fig. 8). Examples are the U. cardui populations in the floodplain forests of the upper Rhine Valley, where the host occurs in relatively stable source-sink systems. In these forests the average density / gall / sample of E. serratulae (mean $=0.744, \mathrm{SE}=+0.069$ was distinctly higher than that of $E$. robusta (mean $=0.427, \mathrm{SE}=+0.052)$. In northern Bavaria (Bayreuth - Pegnitz) $U$. cardui occurs in a fragmented, agriculturally influenced landscape in mostly short-living population systems and metapopulations. Here E. robusta dominated with a mean density of 0.661 , $\mathrm{SE}=+0.04$ over $E$. serratulae $($ mean $=0.364, \mathrm{SE}=+0.043)$. The Belfort-Sundgau region holds an intermediate position (E. serratulae: mean $=0.459, \mathrm{SE}=+0.031$. Eurytoma robusta: mean $=0.638, \mathrm{SE}=+0.027)$. If our whole material collected in western and central Europe (E. serratulae $=772$ gall samples, $E$. robusta $=755$ gall samples $)$ is compared, the average mortality of $U$. cardui due to E. robusta plus the empty cell factor $(=38.9 \%)$ is more than twice as high as that of E. serratulae (14.8\%).

\section{Effect of $E$. serratulae and $E$. robusta on gall growth}

In galls of $U$. cardui the number of $E$. serratulae larvae / gall is positively correlated with the gall diameter $(r=0,428, p<0.001, N=1407)$. But the variable " $E$. serratulae larvae / gall" is also correlated with the variable "cells / gall" ( $r=0,481, p<0.001, N$ 
Table I. The effect of cells / gall and E. serratulae larvae / gall on gall diameter. Multiple regression: dependent variable: gall diameter, $\mathrm{N}=2.733$, multiple $\mathrm{R}=0.67115$, adjusted $\mathrm{R}^{2}=0.45024, \mathrm{SE}=3.02533$.

\begin{tabular}{c|c|c|c|c|c}
\hline Variable & B & SE (B) & Beta & $\boldsymbol{T}$ & Sign \\
\hline cells / gall & 1.15157 & 0.02496 & 0.6606 & 46.147 & $<0.001$ \\
\hline E. serratulae / gall & 0.18681 & 0.04095 & 0.0653 & 4.562 & $<0.001$ \\
\hline (Constant) & 9.00247 & 0.11135 & & 80.851 & $<0.001$ \\
\hline
\end{tabular}

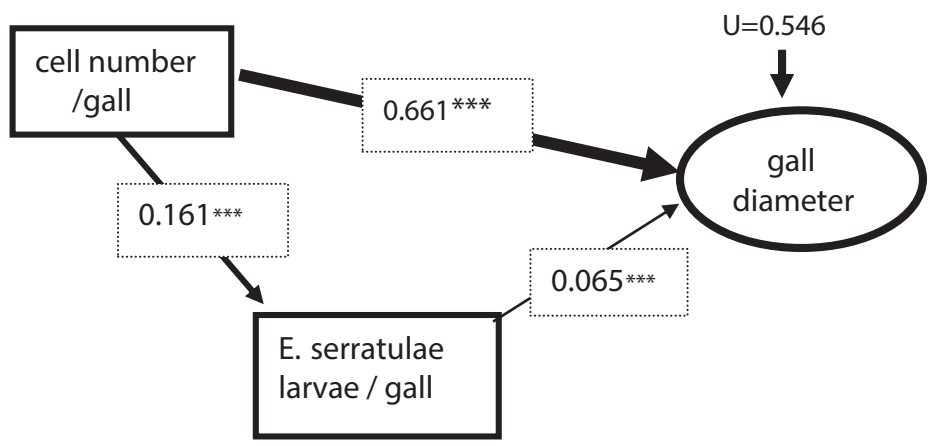

Figure 9. Direct and indirect effects between cells / gall, E. serratulae / gall and gall diameter. Path diagram: all three path coefficients (beta values) are significant at $p<0.001$. Multiple $\mathrm{R}^{2}=0.4546 . \mathrm{U}$ (coefficient of non-determination) $=0.5456(N=2,733 U$. cardui galls with E. serratulae).

$=2733)$, which in turn strongly affects the gall diameter $(r=0,674, p<0.001, N=$ 2733). Together the two variables account for about $45 \%$ of the variation of the gall diameter $\left(\mathrm{R}^{2}=0.454\right)$. A multiple regression (Table 1$)$ and a path analysis allow to separate the effect of the two variables and to calculate the impact of the variable " $E$. serratulae larvae / gall". Fig. 9 shows the three path coefficients ( = standard partial regression coefficients). A comparison of the strength of the coefficients affecting the gall diameter allows the conclusion that the parasitoid larvae / gall can contribute about $10 \%$ to the gall diameter. Since E. serratulae attacks the $U$. cardui larvae before the gall is formed, this effect is not due to the selection of larger galls but to a stimulatory influence on gall growth.

An independent additional test is the comparison of galls with and without parasitoids (Fig. 10). Multivariate tests (GLM, Wilks-Lamda) for the gall size classes 2-5 $(2=158,3=158,4=84,5=45$ galls, $\mathrm{DF}=441)$ indicate $(F=14.364$ and $p<0.001)$ a high statistical significance: Galls parasitized exclusively by $E$. serratulae have larger diameters than unparasitized galls and galls parasitized exclusively by E. robusta have lesser diameters than galls without parasitoids. This negative effect of $E$. robusta is not due to an ovipositional preference for smaller galls but to a premature elimination of young Urophora larvae that results in empty cells (Johannesen and Seitz 2003a, Zwölfer et al. 2007). 
Table 2. Correlation of body weight of unparasitized $U$. cardui and E. serratulae larvae within $U$. cardui mummies with gall parameters.

\begin{tabular}{c|c|c}
\hline & $\boldsymbol{U}$ c cardui $(\boldsymbol{N}=\mathbf{6 6})$ & E.serratulae $(\boldsymbol{N}=\mathbf{1 5})$ \\
\hline Weight $(\mathrm{mg})$ vs gall length $(\mathrm{mm})$ & & \\
\hline$r$ & $0.0892(p=0.464)$ & $\mathbf{0 . 8 4 5 2}(\boldsymbol{p}=\mathbf{0 . 0 0 0 1})$ \\
\hline slope & $0.048(\mathrm{SE}=0.067)$ & $0.2253(\mathrm{SE}=0.0395)$ \\
\hline Weight $(\mathrm{mg})$ vs gall diameter $(\mathrm{mm})$ & & $\mathbf{0 . 6 2 3 3}(\boldsymbol{p}=\mathbf{0 . 0 1 3})$ \\
\hline$r$ & $0.1701(p=0.1722)$ & $0.4503(\mathrm{SE}=0.1561)$ \\
\hline slope & $0.1972(\mathrm{SE}=0.1428)$ & \\
\hline Weight $(\mathrm{mg})$ vs cell sum/gall & & $\mathbf{0 . 5 6 3 3}(\boldsymbol{p}=\mathbf{0 . 0 3 9 3})$ \\
\hline$r$ & $0.0679(p=0.588)$ & $1.1746(\mathrm{SE}=0.5127)$ \\
\hline slope & $-0.2201(\mathrm{SE}=0.4043)$ &
\end{tabular}

In a subsample of 81 galls we assessed larval biomass of the host and E. serratulae, gall diameter and length, and cell sum / gall. The average fresh weight of 66 mature unparasitized third instar larvae of $U$. cardui was $13.465 \mathrm{mg}(\mathrm{SE}=+0.545 \mathrm{mg})$ and that of 15 full grown $E$. serratulae larvae (inclusive of the sclerotized host skins) 5.207 $\mathrm{mg}(\mathrm{SE}=+0.452 \mathrm{mg})$. Gall length (mean $24.302 \mathrm{~mm}, \mathrm{SE}=+0.88 \mathrm{~mm})$ ranged from 14.8 to $35.2 \mathrm{~mm}$. Gall diameters (mean $13.82 \mathrm{~mm}, \mathrm{SE}=+0.408 \mathrm{~mm}$ ) ranged from 7.9 to $20.3 \mathrm{~mm}$. Correlations of larval weight of E. serratulae in sclerotized host skins with the gall parameters diameter, length, and cell sum produced positive correlations (Table 2). We interpret this difference as another indication that host larvae, under the influence of the endoparasitoid E. serratulae, stimulate gall growth more strongly than $U$. cardui larvae without the endoparasitoid.

\section{Discussion}

Mechanisms allowing a balance in multi-parasitoid systems are compensations between intrinsic and extrinsic superiorities (Smith 1929). Examples can be found in most parasitoid complexes where parasitoid species with different life histories competitively coexist (e.g. Zwölfer and Kraus 1957, Askew 1968, Godfray 1994). Another important aspect is the temporal niche divergence of coexisting parasitoids, i.e. the exploitation of different host stages (e.g. Pschorn-Walcher and Altenhoffer 1989) or different developmental phases of plant galls (e.g. Askew 1975). Simulation models (Hassell 1986, 2000) demonstrate that patchy host distributions, metapopulation structures and host refuges may stabilize parasitoid-host interactions and contribute to prevent overexploitation of host populations.

In our study we show that the particular characteristics of multilocular plant galls provide an additional stabilizing mechanism for competing parasitoid species, since the two Eurytoma species exploit the cells of an individual gall in different ways. Eurytoma robusta is intrinsically superior, i.e. where its larva comes into contact with an $U$. cardui larva containing a young E. serratulae, it eliminates both. An advantage is also the ca- 
pacity of the E. robusta larva to feed as an inquiline on the nutritive tissues of the gall. For its oviposition E. robusta is dependent on galls with fully developed cells, where synchronisation problems can lead to mortality of the young host larvae and starvation of the E. robusta larvae. Frequent and often high superparasitism of E. robusta (Zwölfer et al. 2007) can result in a considerable waste of eggs. As an initiator of empty cells $E$. robusta is an important mortality factor of $U$. cardui (Fig. 8). Parasitism by E. robusta and empty cells due to host killing without successful development of the parasitoid larva can cause up to $100 \%$ host mortality of small $U$. cardui populations. In experimental $U$. cardui populations in the Swiss Jura (Zwölfer 1994) and in several of our monitored populations in Northern Bavaria (Zwölfer et al. 2007) an overexploitation by E. robusta resulted in the complete breakdown of local $U$. cardui subpopulations and the associated monophagous parasitoid E. serratulae. In such cases its relatively broad host range allows E. robusta to switch to other host species. With regard to its host $U$. cardui, E. robusta is a poorly adapted generalist parasitoid but nevertheless an important mortality factor.

The life history of its congener E. serratulae is perfectly integrated with that of $U$. cardui. The female of E. serratulae detects the young host larvae already before an externally visible gall is formed and is able to parasitize a greater proportion than $E$. robusta of the host larvae available in an individual gall. In this way E. serratulae profits from grown up U. cardui populations with large multi-chambered galls. The capability to induce a sclerotization of host cuticula, once the host larva is consumed, provides a certain protection of the hibernating $E$. serratulae larva, e.g. against hyperparasitoids or predators. The emergence of adults is well synchronized with the emergence of the host flies. The increasing parasitism by E. serratulae in thistle patches with higher gall densities (Fig. 6) indicates a host searching behaviour influenced by the concentration of the host resource. Within a local host population galls with more cells contain over proportionally more E. serratulae larvae. This relationship suggests that thistle shoots with larger clutch sizes of Urophora are better recognizable and more attractive for $E$. serratulae females. The positive density dependence on the macrohabitat and microhabitat levels relieves the host $U$. cardui at low densities and contributes to stabilize a host-parasitoid system (Hassell 2000). Within individual galls the exploitation rate of E. serratulae is inversely density-dependent, making possible an increasing host refuge for $U$. cardui with increasing numbers of cells / gall (Fig. 3). The reason for this inverse relationship may be egg limitation of the E. serratulae females leading to some sort of "predator satiation" and/or the difficulty to locate all the tiny host larvae of a large clutch. The survival advantage of $U$. cardui larvae in galls with higher cell numbers can be important for the population dynamics of the host; as such galls contribute considerably more to the reproductive fitness of $U$. cardui than small galls (Freese and Zwölfer 1996). Since the absolute numbers of E. serratulae / gall also increase, larger galls with higher cell numbers are ultimately profitable to both the parasitoid and the host. Tabuchi and Amano (2004) report a similar relationship for the gall midge Asteralobia sasakii and its parasitoids on Ilex.

A particular feature of E. serratulae is its capacity to contribute to the growth of U. cardui galls (Table 1, Fig. 10). Host manipulation by endoparasitoids is a common 


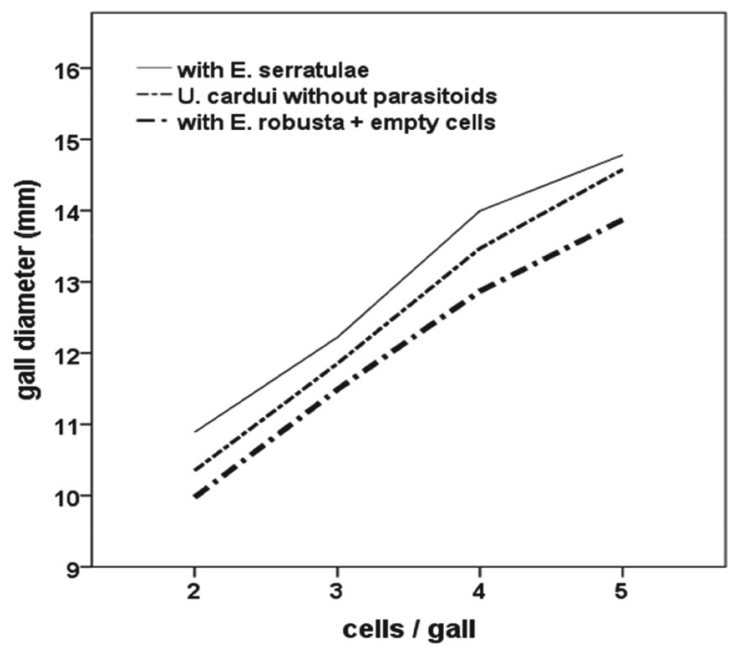

Figure 10. Average gall diameter in galls with E. serratulae (3512 galls), with unparasitized $U$. cardui (3449 galls) and with E.robusta plus empty cells (4288 galls).

phenomenon, as parasites tend to alter their hosts in ways beneficial to their own fitness. A special type of this manipulation consists in the prolongation of the feeding stages of the host, which allows the parasitoid larva to accumulate additional food resources (Beckage and Riddiford 1983, Slansky 1986, Godfray 1994). We assume that $E$. serratulae larvae stimulate $U$. cardui larvae to produce additional gall growth in a comparable way. Since larger galls provide better protection and possibly also an improved nutritional situation for U. cardui (Freese and Zwölfer 1996) they are profitable for both $U$. cardui and E. serratulae. The life history of E. serratulae, and the fact that it was able to follow its host to all three host plants and to cover the whole distribution area of $U$. cardui, indicate that the parasitism of $U$. cardui by E. serratulae forms an evolutionarily ancient and stable association.

It is interesting to compare E. serratulae with Eurytoma obtusiventris Gahan, the monophagous and highly specialised parasitoid of another gall-inducing tephritid, Eurosta solidaginis (Fitch), on North American Solidago spp. (Uhler 1951, Abrahamson et al. 1989, Abrahamson and Weis 1997). Both parasitoid species are koinobiont endoparasitoids, both attack the young host larvae of a gall-maker before gall formation starts, both are more frequent in large host galls and both are exposed to congeneric hyperparasitoids (E. robusta and E. gigantea Walsh, respectively), which deposit their eggs later into the galls. An important difference between the two parasitoid-host systems lies in the gall structure. The multi-chamber gall of $U$. cardui can secure the survival of some host larvae, whereas the single-chamber gall of $E$. solidaginis, once attacked, provides no chance of a host-escape. Differences exist also in the exploitation strategies of the two parasitoids. No influence on gall growth is described for E. obtusiventris; its higher frequency in larger galls is interpreted as a mere result of interactions with other mortality factors of the Eurosta galls (Abrahamson et al. 1989). It might, however, be 
worthwhile checking whether E. obtusiventris larvae could manipulate Eurosta larvae to produce larger goldenrod galls in a comparable way as E. serratulae influences the growth of $U$. cardui galls.

Our study shows that the specialised E. serratulae in its closely-knit and evolutionarily stable parasitoid-host system with $U$. cardui follows a "sustainable" exploitation strategy, which is absent in the poorly adapted generalist E. robusta.

\section{Acknowledgements}

We gratefully acknowledge support by the German Research Foundation (Graduiertenkolleg No. 678 "Bedeutung von Wirk- und Signalstoffen für Tiere - von der Struktur zur Funktion im Ökosystem”). H. Zwölfer thanks Prof. Joe Shorthouse for a suggestion, made many years ago, that endoparasitoids may be able to stimulate gall growth. Two anonymous reviewers of a former version of the manuscript provided helpful criticism.

\section{References}

Abrahamson WG, Sattler JF, McCrea KD, Weis AE (1989) Variation in selection pressures on the golden rod gall fly and the competitive interactions of its natural enemies. Oecologia 79: 15-22. doi: 10.1007/BF00378234

Abrahamson WG, Weis AE (1997) Evolutionary ecology across three trophic levels, goldenrods, gallmakers, and natural enemies. Princeton University Press, Princeton, New Jersey.

Askew RR (1968) A survey of leafminers and their parasites on laburnum. Transactions of the Royal Entomological Society of London 120: 1-37. doi: 10.1111/j.1365-2311.1968. tb00335.x

Askew RR (1975) The organisation of chalcid-dominated parasitoid communities centred upon endophytic hosts.In: Price PW (Ed.) Evolutionary strategies of parasitoids. Plenum Press, New York, 130-153.

Askew RR, Shaw MR (1986) Parasitoid communities: their size, structure and development. In: Waage J, Greathead D (Eds) Insect parasitoids. Academic Press, London, 225-264.

Beckage NE, Riddiford LM (1983) Growth and development of the endoparasitic wasp Apanteles congregatus, dependence on host nutritional status and parasitoid load. Physiological Entomology 8: 231-241. doi: 10.1111/j.1365-3032.1983.tb00355.x

Claridge MF (1961) Biological observations on some eurytomid (Hym. Chalcidoidea) parasites associated with Compositae, and some taxonomic implications. Proceedings of the Royal Entomological Society of London (A) 36: 153-158. doi: 10.1111/j.1365-3032.1961. tb00261.x

Eber S, Brandl R (1994) Ecological and genetic spatial patterns of Urophora cardui (Diptera: Tephritidae) as evidence for population structure and biogeographical processes. Journal of Animal Ecology 63: 187-199. doi: 10.2307/5594 
Fisher RC (1961) A study in insect multiparasitism. II the mechanism and control of competition for possession of the host. Journal of experimental Biology 38: 605-628.

Freese G, Zwölfer H (1996) The problem of optimal clutch size in a tritrophic system: the oviposition strategy of the thistle gall fly Urophora cardui (Dipt. Tephritidae). Oecologia 108: 293-302. doi: 10.1007/BF00334654

Frenzel M, Eber S, Klotz S, Brandl R (2000) Ecological comparisons across geographical distributions: the thistle gall fly Urophora cardui (Diptera: Tephritidae) on different Cirsium hosts. European Journal of Entomology 97: 183-189. doi: 10.14411/eje.2000.035

Godfray HCJ (1994) Parasitoids. Behavioural and Evolutionary Ecology. University Press, Princton.

Hassell MP (1986) Parasitoids and population regulation. In: Waage KJ, Greathead D (Eds) Insect parasitoids. Academic Press, London, 201-224.

Hassell MP (2000) The Spatial and Temporal Dynamics of Host-parasitoid Interactions. Oxford University Press.

Johannesen J, Seitz A (2003a) Larval distributions of the ectoparasitoid wasp Eurytoma robusta relative to the host tephritid gall fly Urophora cardui. Entomologia experimentalis et applicata: 107: 47-55. doi: 10.1046/j.1570-7458.2003.00040.x

Johannesen J, Seitz A (2003b) Comparative population genetic structures of the fruit fly Urophora cardui and its primary parasitoid Eurytoma robusta. Entomologia experimentalis et applicata 107: 149-157. doi: 10.1046/j.1570-7458.2003.00077.x

Mayr G (1878) Arten der Chalcidier-Gattung Eurytoma durch Zucht erhalten. Verhandlungen der zoologisch-botanischen Gesellschaft Wien 28: 297-334.

Price PW, Clancy KM (1986) Interactions among three trophic levels: galls size and parasitoid attack. Ecology 6: 1539-1600.

Pschorn-Walcher H, Altenhofer E (1989) The parasitoid community of leaf-mining sawflies (Fenusini and Heterarthrini): A comparative analysis. Zoologischer Anzeiger 222: 37-57.

Redfern M (1983) Insects and thistles. Naturalists' Handbooks 4, Press Syndicate of the University of Cambridge.

Redfern M, Askew RR (1992) Plant Galls. Naturalists' Handbooks 17, Press Syndicate of the University of Cambridge.

Saccheri I, Hanski I (2006) Natural selection and population dynamics. Trends in Ecology and Evolution 21: 341-347. doi: 10.1016/j.tree.2006.03.018

Slansky F (1986) Nutritional ecology of endoparasitic insects and their hosts: an overview. Journal of Insect Physiology 32: 255-261. doi: 10.1016/0022-1910(86)90036-3

Smith HS (1929) Multiple parasitism: its relation to the biological control of insect pests. Bulletin of Entomological Research 20: 141-149. doi: 10.1017/S0007485300021040

Sokal RR, Rohlf FJ (1981) Biometry, second edition. Freeman and Company, San Francisco.

Tabuchi K, Amano H (2004) Impact of differential parasitoid attack on the number of chambers in multilocular galls of two closely related gall midges (Diptera: Cecidomyiidae). Evolutionary Ecology Research 6: 695-707.

Uhler LD (1951) Biology and ecology of the golden rod gall fly, Eurosta solidaginis (Fitch). Memoir 300, Cornell University Agricultural Experiment Station, Ithaca, New York, $1-51$. 
Vikberg V (2005) Orakärpänen (Urophora cardui) ja sen kiilukaisloiset Etelä-Suomessa (Hymenoptera: Chalcidoidea: Eulophidae, Eupelmidae, Eurytomidae, Pteromalidae, Torymidae). Sahlbergia 10: 30-49.

Zerova MD, Seryogina LY (2006) A review of the Palaearctic species of the genus Eurytoma, belonging to the E. robusta species group (Hymenoptera, Eurytomidae), with description of two new species. Entomological Review 86:695-705. doi: 10.1134/S001387380606008X

Zwölfer H (1979) Strategies and counterstrategies in insect population systems competing for space and food in flower heads and plant galls. Fortschritte der Zoologie 25: 331-353.

Zwölfer H (1988) Evolutionary and ecological relationships of the insect fauna of thistles. Annual Review of Entomology 33: 103-22. doi: 10.1146/annurev.en.33.010188.000535

Zwölfer H (1994) Structure and biomass transfer in food webs: stability, fluctuations, and network control. In: Schulze (Ed.) Flux control in biological systems from enzymes to populations and ecosystems. Academic Press Inc., San Diego, 365-419.

Zwölfer H, Arnold-Rinehart J (1993) The evolution of interactions and diversity in plant-insect systems. The Urophora-Eurytoma food web in galls on Palearctic Cardueae. Ecological Studies, Springer, Berlin, Heidelberg, New York 99: 211-233.

Zwölfer H, Böheim M, Beck E (2007) Eurytoma robusta (Hymenoptera: Eurytomidae), a local key factor in the population dynamics of Urophora cardui (Diptera: Tephritidae): A comparative analysis. European Journal of Entomology 104: 217-224. doi: 10.14411/ eje. 2007.034

Zwölfer H, Kraus M (1957) Biocoentic studies on the parasites of two fir- and two oak-tortricids. Entomophaga 2: 173-196. doi: 10.1007/BF02372436 